\title{
Usage of the cyto-genetics and cytology to identify the action mechanisms of two bio- fertilizers on Allium cepa meristematic cells
}

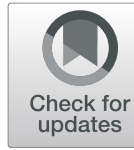

\author{
Rania T. Ali (D), Enas M. Abdel-Ghany, Fawzia I. Mohamed, Evon M. Hanna and Zeinab M. Elashery
}

\begin{abstract}
Background: Bio-fertilizers as a safe alternative to the synthetic fertilizers come to the front in the agriculture requirements as they provide the planted crops with their nutrients to ensure high quality and productivity. Many of them must be screened and examined to configure their effect on the plants.

Results: This study was designed to evaluate two promising bio-fertilizers: Moringa oleifera leaf extract (5.0, 10.0, 20.0\%) and Sacharomyces cerevisiae aqueous extract (5.0, 10.0, 20.0\%) for their safe usage on Allium cepa root meristems as a model system for monocots after $3.0 \mathrm{~h}$ of direct treatment. This evaluation focused on both cytogenetic and cytological levels. Cytogenetic studies screened the effect of each extract on the mitotic apparatus considering the mitotic index, mitotic phase index, percentage, and type of abnormalities. Cytological studies with transmission electronic microscope screen the effect of each extract on ultra-structural organelles (mitochondria, endoplasmic reticulum, peroxisomes, dictyosomes in addition to the vacuoles) in the cell cytoplasm. Obtained data revealed that the yeast extract shows a remarkable cytological effect on cytoplasmic organelles. By the same time, only the higher used concentration of Moringa extract shows higher chromotoxic effect on chromosomal DNA despite it shows high proliferation effect on the treated root tip cells.
\end{abstract}

Conclusion: Among the two tested bio-fertilizers, the Moringa extract in lower concentration is more preferable as it does not harm neither the cytoplasmic organelles nor the mitotic apparatus.

Keywords: Bio-fertilizers, Mitosis, Cytotoxicity, Transmission electronic microscope, Cytoplasmic organelles

\section{Introduction}

The increased awareness of the environmental problems associated with the farmers and plant breeder activities in agriculture to ensure his food requirements, such as depending on synthetic fertilizers and pesticides which were previously proved to pollute the soil and irrigation canals and reduce the crops' quality and productivity, attempted researchers to reconsider the nature resources gifts as much safer alternatives over the currently used synthetic products. In this way, bio-organic fertilizers (as a source of input plant nutrients) may replace the synthetic ones. They can hopefully solve the dilemma of the obligatory needs for plant nutrient supplement without damaging the plant earth ecosystem or crops' quality, due to their high productivity, high nutritive value, anti-

\footnotetext{
* Correspondence: raniatawfick@hotmail.com

Genetics \& Cytology Department, National Research Centre, Cairo, Egypt
}

oxidant effect, easy preparation, low cost, and environmentally safe (Phiri 2010).

Moringa oleifera is one of such promising alternatives being investigated to ascertain its effect on both growth and yield of crops and thus can be promoted among farmers as a possible supplement or substitute to inorganic fertilizers (Phiri 2010), e.g., Moringa leaf and twig extract increases the contents of growth-promoting hormones (auxins, gibberellins, and cytokinins) in Eruca vesicaria subsp. sativa (rocket or arugula) progressively above those of the corresponding controls in a dose-related manner (Abdalla 2013).

Moringa leaf extract was sprayed onto the leaves of onions, bell pepper, soya beans, sorghum, coffee, tea, chili, melon, and maize. It was shown to increase yields of these crops (Fuglie 2000). Moringa extract products can be employed either as root tips, soil drenches, or foliar sprays. 
On the other hand, Sacharomyces cerevisiae (bread yeast) also is considered as a type of bio-fertilizer which is usually added to the soil or as foliar application on vegetable crops because of its nutrition properties as well as its substances like growth regulators such as gibberellins and auxins (Sarhan and Sharif 1988) and its ability to produce a group of essential enzymes (Dinkha and Elkhazraji, 1990).

Active dry yeast is considered as a bio-stimulant, natural source of cytokinins that stimulate cell division and enlargement as well as the synthesis of protein, nucleic acid, and chlorophyll formation (Wanas 2006). It may enhance water holding capacity, increase antioxidants, and enhance the metabolism (Abbas 2013).

The objective of the current study is to test the effect of Moringa leaf extract and bread yeast aqueous extract as two bio-fertilizers on the somatic cell division and on some cytoplasmic organelles such as the mitochondria of Allium cepa plant as a model system in order to configure its mode of action on monocot plants.

\section{Materials and methods Plant materials}

The Allium cepa $(2 \mathrm{n}=16)$ onions (Var. red, Giza) were used for all the conducted experiments and were obtained from the Crop Research Institute, Agricultural Research Centre, Giza, Egypt.

\section{Chemicals and experimental extracts}

The chemicals for cytogenetic studies were prepared according to Sharma and Sharma (1980) with some modifications. The chemicals for cytological studies with transmission electronic microscope were prepared according to Reynold (1963) with some modifications. One hundred percent of Moringa plant extract was kindly prepared and obtained by The Plant Moringa Propagation Unit, National Research Center, Giza, Egypt.

One hundred percent of yeast extract is prepared in the cytology and cytogenetics lab, NRC, Egypt, after Hanafy et al.'s (2012) prescription as follows: various concentrations (5.0, 10.0, and $20.0 \mathrm{~g}$ ) of yeast were weighed and put with $25.0 \mathrm{~cm}^{3}$ of water with a teaspoon full of sugar in glass beakers. The beakers of each concentration were kept in a dark warm place for $30 \mathrm{~min}$, contents of the beakers were then filtered into a measuring flask, and water was added to $100.0 \mathrm{~cm}$ final volume for each one.

\section{Treatment with the tested materials}

The designed experiment was carried out on benchtop in cytology and cytogenetics lab, NRC, Egypt, as follows: about $2.0 \mathrm{~cm}$ length main roots of onion bulbs were treated for $3.0 \mathrm{~h}$ with the experimented materials for each concentration at room temperature and then divided into two groups for cytogenetic studies and cytological studies.

\section{For cytogenetic studies}

The roots were fixed with Carnoy's fixative for $24 \mathrm{~h}$ and then preserved in $70.0 \%$ alcohol ready to be examined (Sharma and Sharma 1980). About 3000 of onion root tip meristem cells were scored and observed under an Olympus light microscope for each treatment. Mitotic index was computed by determining the mitotic cell frequency at the root tip cells as:

$$
\text { Mitotic index }=\frac{\text { Number of dividing cells }}{\times 100}
$$

Cytological abnormalities at the appropriate mitotic stages were also observed and scored.

\section{For cytological studies}

This part of the study has been carried out in TEM lab CURP (Cairo University Research Park - Faculty of Agriculture). In summary, the roots were fixed in $5.0 \%$ gluteraldehyds in $0.1 \mathrm{M}$ sodium cacodylate buffer, $7.3 \mathrm{pH}$; post-fixed in $1 \%$ osmium tetroxide in $0.1 \mathrm{ml}$ sodium cacodylate buffer; immersed in a mixture of resin and propylene oxide; stained in toluidine blue for light microscope examination prior to final trimming; stained for ultra-thin sections: uranyl acetate $30 \mathrm{~min}$ followed by lead citrate for $15 \mathrm{~min}$. The ultra-thin sections of tissue were stained with uranyl acetate and lead citrate and then examined by transmission electron microscope JEOL (JEM-1400 TEM) at the candidate magnification. Images were captured by CCD camera model AMT, optronics camera with $1632 \times 1632$ pixel formate as a side mount configuration. This camera uses a 1394 firewire board for acquisition.

\section{Results}

Table 1 revealed an increase in the mitotic index values after treating the onion roots for $3 \mathrm{~h}$ with aqueous Moringa leaf extract in the two higher used concentrations; if compared with the control, the maximum mitotic index (11.63) was recorded after treatment with $10.0 \%$ Moringa extract followed by the mitotic index 9.28 recorded after $20.0 \%$ while treatment with $5.0 \%$ extract barely affect the mitotic index (8.03).

On the other hand, 3-h treatment with bread yeast extract shows a concentration-dependent reduction of mitotic index values (8.84, 7.94, and 6.26).

As illustrated in Table 1, although the treatment with 5.0\% Moringa extract did not affect the mitotic index, it shows an increase in prophase frequency to reach $46.4 \%$ on the response of metaphase (8.02\%) and ana- 
Table 1 Mitotic and phase indexes and percentages of abnormal mitosis and abnormality in each mitotic phase in Allium cepa root tip meristems, after $3 \mathrm{~h}$ treatment with Moringa oleifera and Sacharomyces cerevisiae extracts

\begin{tabular}{|c|c|c|c|c|c|c|c|c|c|}
\hline \multirow[t]{2}{*}{ Treatment } & \multirow{2}{*}{$\begin{array}{l}\text { Mitotic } \\
\text { index } \pm \text { SE }\end{array}$} & \multirow{2}{*}{$\begin{array}{l}\text { Percent of } \\
\text { abn. } \\
\text { interphase } \\
\text { cells }\end{array}$} & \multirow{2}{*}{$\begin{array}{l}\text { Percent of } \\
\text { abn. } \\
\text { mitoses } \pm \\
\text { SE }\end{array}$} & \multicolumn{2}{|c|}{ Prophase } & \multicolumn{2}{|c|}{ Metaphase } & \multicolumn{2}{|c|}{ Ana-telophase } \\
\hline & & & & Index & Percent of abn. & Index & Percent of abn. & Index & Percent of abn. \\
\hline Control & $8.40 \pm 0.69$ & 0.00 & 6.34 & 34.920 & 3.41 & 12.70 & 9.40 & 52.38 & 7.58 \\
\hline \multicolumn{10}{|c|}{ Moringa oleifera } \\
\hline $5.0 \%$ & $8.03 \pm 0.59$ & 0.15 & $14.35 \pm 0.12$ & 46.41 & 6.36 & 8.02 & 31.58 & 45.57 & 19.44 \\
\hline $10.0 \%$ & $11.63 \pm 1.07$ & 0.13 & $15.92 \pm 0.49$ & 37.58 & 3.39 & 9.87 & 64.52 & 52.55 & 15.76 \\
\hline $20.0 \%$ & $9.29 \pm 2.03$ & 0.00 & $24.65 \pm 0.32$ & 22.66 & 1.25 & 25.50 & 38.89 & 51.84 & 27.87 \\
\hline \multicolumn{10}{|c|}{ Sacharomyces cerevisiae } \\
\hline $5.0 \%$ & $8.84 \pm 0.84$ & 0.04 & $10.42 \pm 0.49$ & 25.42 & 6.56 & 11.25 & 7.41 & 63.33 & 12.5 \\
\hline $10.0 \%$ & $7.93 \pm 0.84$ & 0.11 & $15.13 \pm 0.42$ & 13.45 & 9.375 & 20.17 & 22.92 & 66.39 & 13.92 \\
\hline $20.0 \%$ & $6.26 \pm 1.08$ & 0.00 & $12.78 \pm 0.21$ & 16.48 & 0.00 & 20.09 & 25.00 & 63.47 & 12.23 \\
\hline
\end{tabular}

Abn abnormality, SE standard error

telophases (45.57\%). This mode of action was reversed after the treatment with $20.0 \%$ Moringa extract, as there was a notable decrease in the prophase frequency on the response of metaphase frequency; the same was regarded after all treatment with the bread yeast extract concentrations on the mitotic phase duration.

Table 1 also reveals that all concentration treatments with each of the two examined materials increase the percentages of abnormal dividing cell of the onion root meristems. The 3-h treatment with Moringa extract was the most destructive, since it induced concentrationdependent increases in the percentages of abnormal mitoses reach $24.64 \%$ after treatment with $20.0 \%$ concentration, worth to mention that the concentration $20.0 \%$ of Moringa extract induces twice the percentage induced after the same used concentration of bread yeast extract.

Table 1 also illustrates that all concentration treatments with each of the two examined extracts exerted the highest percentage of abnormalities at the metaphase stage; these percentages declined at the ana-telophase stage except after treatment with $5.0 \%$ of bread yeast extract.

As illustrated in Fig. 1 the cytological investigations revealed that both tested materials induced a wide range of abnormalities distributed among the different mitotic

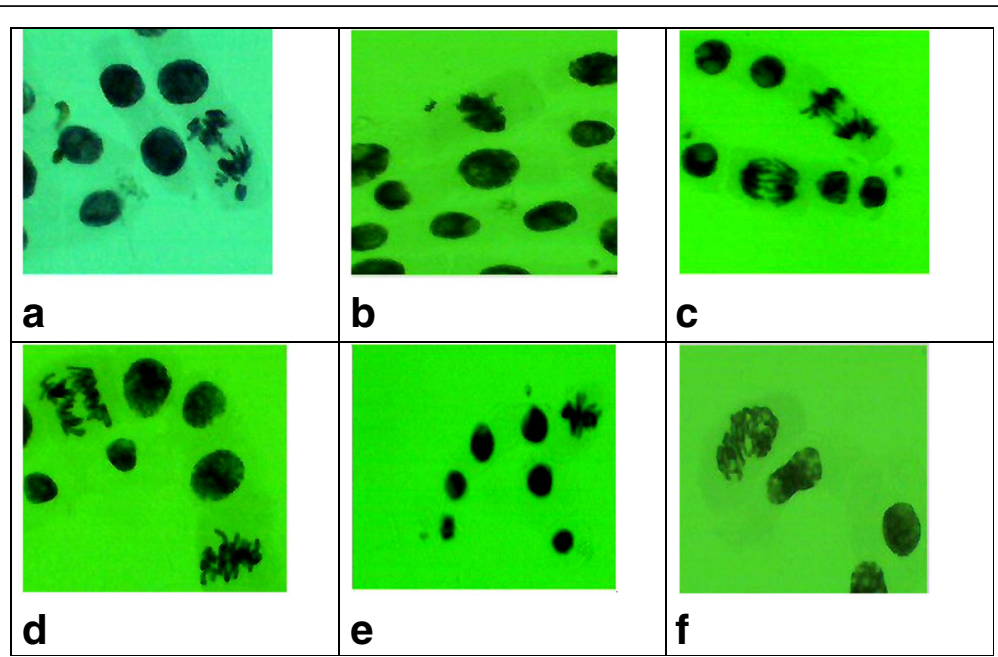

Fig. 1 a-c: Allium cepa root tip meristems after three hr of Moringa extracts. Micronucleus in resting cell and other split anaphase cell with structural bridge and a micronucleus after treatment with 10.0\% Moringa extract (a), Sever sticky metaphase cell after treatment with 20.0\% Moringa extract (b) and Two anaphase cells with partial stickiness and structural bridges after treatment with 10.0\% Moringa extract (c). d-f: Allium cepa root tip meristems after three hr of bread yeast extracts. Two disturbed anaphases with structural bridges after treatment with $20.0 \%$ yeast extract $(\mathbf{d})$, Severe sticky metaphase after treatment with $10 \%$ yeast extract (e) and Disturbed prophase after treatment with $5.0 \%$ bread yeast extract $(\mathbf{f})$ 
stages (Table 2). These abnormalities can be classified into three groups arranged in the following general order of frequencies: chromatin material liquefaction abnormalities > chromosomes kinetic abnormalities > chromosomal structural aberrations, followed by less frequent dividing cells with micronuclei noticed only after treatment with $10.0 \%$ Moringa extract by the percentage of $0.6 \%$.

Chromatin material liquefaction comprised of chromosome stickiness (Fig. 1) and sticky bridges. Generally, cells suffering stickiness of the chromosomes dominated. Stickiness was the most frequent abnormality observed after all concentrations of both tested materials, worth to mention that Moringa extract was the most destructive, since it induced the higher proceeding percentage (5.91, 6.37, and $23.23 \%$ ) of mitotic cells suffering stickiness of the chromosomes.

Chromosomes' kinetic abnormalities comprised of cells with disturbed chromosomes (Fig. 1) and cells with lagging chromosomes (Fig. 1) in addition to clumped chromosomes at metaphases. As illustrated in Table 2, Moringa extract treatment in the three concentrations produces concentration-dependent lowered percentages of normal disturbance (Fig. 2) and clumped metaphases reach $1.13 \%$ after treatment with $20.0 \%$, while the lagging chromosomes as a type of disturbance did not exist.

On the other side, the yeast extract produces considerable percentages of disturbance in its three forms compared with Moringa extracts and control; these percentages were not concentration dependent as it reaches $3.65 .0 \%$ after treatment with $20.0 \%$ concentration which exceeds the percentage of disturbance induced by the same concentration of Moringa by nearly twice its value.
The obtained data revealed that the two tested materials were safe without mentioned clastogenic effect if compared with the control. A very ignorable percentage of micronucleus in mitosis was recorded only after treatment with $10.0 \%$ Moringa extract.

On the level of cytological investigations with transmission electronic microscope, Figs. 3 and 4 show that Moringa extract in its two lower concentrations found to be a much safer extract with non-mentioned stress on the ultrastructural organelles in the cell cytoplasm (clear cytoplasm, normal-sized nucleus, normal endoplasmic reticulum extended normally in the cytoplasm, mitochondria in healthy figure with no lysis or pores or degradation, normal dictyosomes, and small clear vacuoles) if compared with control (Fig. 2), only by the exception of the appearance of peroxisomes after treatment with $10.0 \%$ of Moringa extract. Raising the concentration of Moringa extract to $20.0 \%$ shows its effect on the clearance of the cytoplasm which became cloudy with hardly distinguishable organelles, many small vacuoles, peroxisomes, and other small organelles with crystal shiny core suspected to be electron-translucent bodies (Fig. 5).

On the other hand, treatment with bread yeast extract declares its effect on cytoplasmic organelles even after the lowest used concentration as it affected the cytoplasm to be much turbid and cloudy with a dilated endoplasmic reticulum weakly folded around the mitochondria and many small autophagic vacuoles with organelles engulfed in it, in addition to the presence of peroxisomes (Fig. 6). By exceeding the yeast extract concentrations to 10 and $20.0 \%$, their effects on the cytoplasmic organelles became much fatal as it induces cytoplasm shrinkage away from cell wall, accumulated endoplasmic reticulum folded around

Table 2 Percentage of the different types of abnormalities/scored number, occurring in the mitoses of Allium cepa root tip meristems, after $3 \mathrm{~h}$ treatment with Moringa oleifera and Sacharomyces cerevisiae extract

\begin{tabular}{|c|c|c|c|c|c|c|c|c|c|c|c|}
\hline \multirow[t]{4}{*}{ Treatment } & \multicolumn{11}{|c|}{ Percent of different types of abnormal mitoses/scored number } \\
\hline & \multicolumn{3}{|c|}{ Chromat. mater. Liquefac. abn. } & \multicolumn{4}{|c|}{ Chromos. kinetic abnormality } & \multicolumn{3}{|c|}{ Chrom. structural aberr. } & \multirow{3}{*}{$\begin{array}{l}\text { Micro- } \\
\text { nu. }\end{array}$} \\
\hline & \multirow[t]{2}{*}{ Sti. } & \multirow[t]{2}{*}{ Sti.br. } & \multirow[t]{2}{*}{ Sum. } & \multicolumn{2}{|l|}{ Dist. } & \multirow[t]{2}{*}{ Lag. } & \multirow[t]{2}{*}{ Sum. } & \multirow[t]{2}{*}{ Str.br. } & \multirow{2}{*}{$\begin{array}{l}\text { Frag. \& } \\
\text { break. }\end{array}$} & \multirow[t]{2}{*}{ Sum. } & \\
\hline & & & & Dist. & Clump. & & & & & & \\
\hline Control & 0.40 & 0.40 & 0.80 & 3.90 & 0.00 & 0.40 & 4.30 & 0.00 & 0.80 & 0.80 & \\
\hline \multicolumn{12}{|c|}{ Moringa oleifera } \\
\hline $5.0 \%$ & 5.91 & 0.00 & 5.91 & 8.02 & 0.00 & 0.00 & 8.02 & 0.00 & 0.00 & 0.00 & 0.00 \\
\hline $10.0 \%$ & 6.05 & 0.32 & 6.37 & 5.41 & 2.55 & 0.00 & 7.96 & 0.32 & 0.64 & 0.95 & 0.56 \\
\hline $20.0 \%$ & 21.81 & 1.42 & 23.23 & 0.57 & 0.57 & 0.00 & 1.13 & 0.28 & 0.28 & 0.56 & 0.00 \\
\hline \multicolumn{12}{|c|}{ Sacharomyces cerevisiae } \\
\hline $5.0 \%$ & 7.08 & 0.00 & 7.08 & 2.50 & 0.00 & 0.00 & 2.50 & 0.83 & 0.00 & 0.83 & 0.00 \\
\hline $10.0 \%$ & 10.08 & 2.10 & 12.18 & 1.68 & 0.00 & 0.42 & 2.10 & 0.00 & 0.84 & 0.84 & 0.00 \\
\hline $20.0 \%$ & 7.31 & 2.74 & 10.05 & 2.74 & 0.46 & 0.46 & 3.65 & 0.91 & 0.00 & 0.91 & 0.00 \\
\hline
\end{tabular}

Chromat. mater. Liquefac chromatin material liquefaction, Sti. sticky, Sti.br. sticky bridge, Chromos. kinetic abnormality chromosome kinetic abnormality, Dist. disturbancy, Lag. laggard chromosome, Clump. clumped chromosome, Chrom. structural aberr. chromosomes structural aberrations, Str.br. structural bridge, micronu micronucleus, Frag. \& break. fragment and breakage 


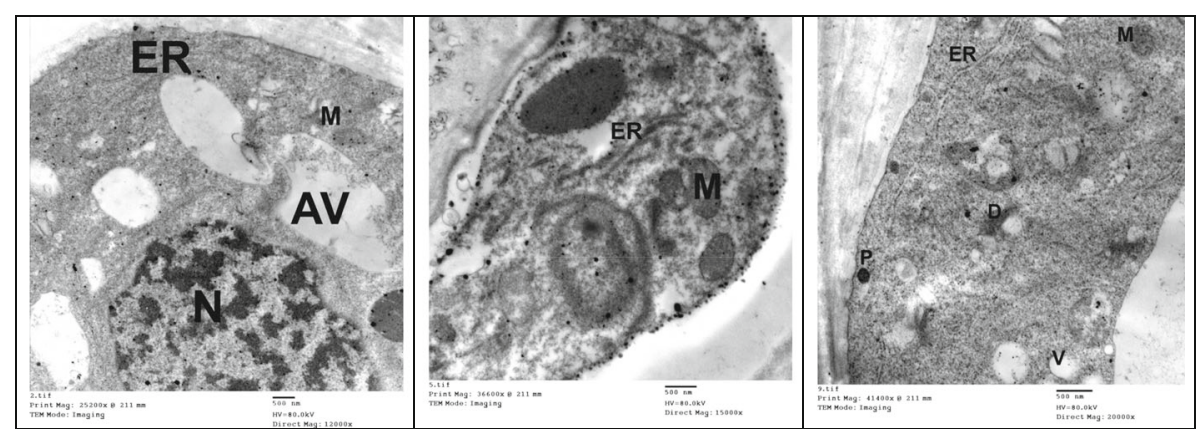

Fig. 2 Ultra-thin section in Allium cepa root tip meristems as control. The normal cell organelles: nucleus (N), mitochondria (M), dictyosomes (D), peroxisomes (P), and endoplasmic reticulum (ER) in addition to vacuole $(V)$ and autophagic vacuoles (AV)

partially degraded mitochondria, and huge autophagic vacuoles (Figs. 7 and 8 ).

\section{Discussion}

The mitotic index variations as a parameter for cytotoxicity used as indicators of adequate cell proliferation (Gadano et al. 2002) and the types of chromosomal aberrations and their frequency used as a parameter for the genotoxic effects of the tested materials were analyzed and illustrated in Tables 1 and 2 and Fig. 1.

The increase in mitotic index values after the treatment of the onion roots for $3 \mathrm{~h}$ with Moringa leaf extract in the two higher concentrations compared with control may be due to the enrichment contents of growth-promoting hormones (auxins, gibberellins, and cytokinins) in Moringa extract (Abdalla 2013), and it may reflect the Moringa effect on DNA biosynthesis and the other substances required for cell division (El-Awadi 1996).

The yeast extract mito-depressive action may be due to a negative interference of this alcoholic extract with specific proteins and enzymes which mediate DNA polymerase (Hidalgo et al. 1989), DNA synthesis, blockage in the G2 phase of the cell cycle, inhibiting the cell to enter into divisional phases $(0.4 \% v / v$ concentration of ethyl alcohol was proved earlier to delay the cell cycle for $13 \mathrm{~h}$ after given to the root tips of Allium cepa for $2 \mathrm{~h}$, this delay cover the $\mathrm{S}$ and $\mathrm{G}$ phases (Arcara and Ronchi, 2014)), microtubule formation, impaired nucleoprotein synthesis, and reduced level of ATP to provide energy for spindle elongation, microtubule dynamics, and chromosomal movement (Majewska et al. 2003; Türkoğlu 2012; Gagliardi and Shain 2013).

There was a notable decrease in the prophase frequency on the response of metaphase frequency, after treatment with $20.0 \%$ Moringa extract and all treatment with the bread yeast extract concentrations on the mitotic phase duration. Similar effect on the phase frequency was observed previously by Ali (2009) after treatment of Vicia faba roots with the extract of " $S$. bicolor seedlings extract," author attributed this effect to be due to the hinder of DNA synthesis rather than retardation of the spindle formation, where MI depression was not accompanied by lowering the metaphase and anaphase (same as yeast extract in all concentration).

The increase in metaphase and ana-telophase percentage could be the result from the lengthening of their

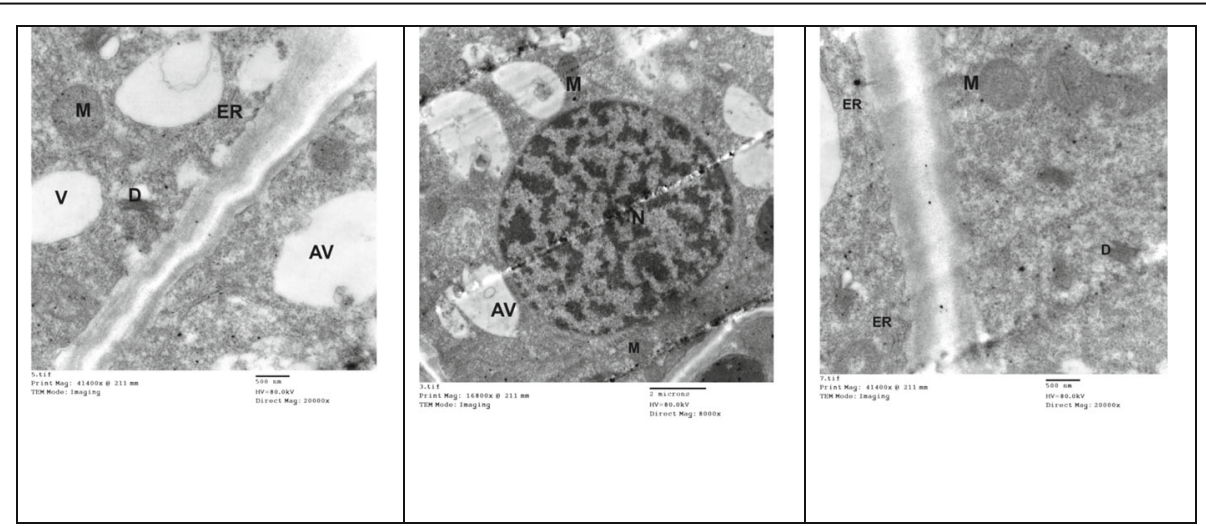

Fig. 3 Ultra-thin section in Allium cepa root tip meristems shows the effect of $3 \mathrm{~h}$ of direct treatment with 5.0\% Moringa leaf extract on cell organelles: normal size nucleus (N), mitochondria (M), dictyosomes (D), and endoplasmic reticulum (ER) in addition to vacuole $(V)$ and autophagic vacuoles (AV) 


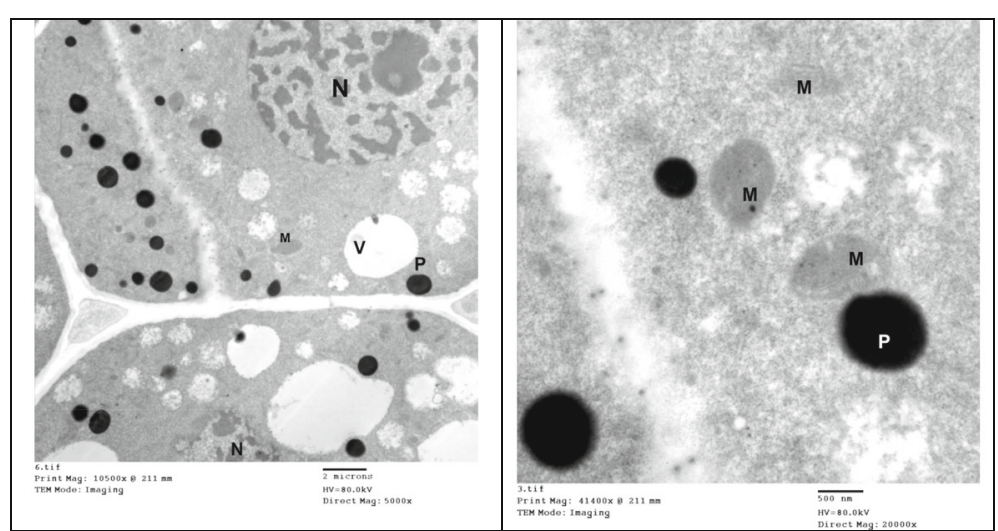

Fig. 4 Ultra-thin section in Allium cepa root tip meristems shows the effect of $3 \mathrm{~h}$ of direct treatment with 10.0\% Moringa extract on cell organelles: normal size nucleus $(N)$, mitochondria $(M)$, and peroxisomes $(P)$ in large numbers in addition to vacuole $(V)$

duration that leads to their accumulation (Abdel-Salam et al., 1997).

Worth to mention that the alcohol produced by the yeast fermentation changes the $\mathrm{PH}$ of its extract; this $\mathrm{PH}$ acts as a controlling factor for microtubule disassembly/ assembly probability ratios, as well as it controls its polymerization and depolymerization during metaphase chromosome orientation. This, in turn, controls the timing and dynamics of post-attachment mitotic chromosome motions through metaphase (Gagliardi and Shain 2013); this in turn affects the lengthening of metaphase and anaphase duration.

Considering the chromosomal aberrations as an indicator for the mutagenic effect of the tested materials on the following:

1. Chromosome DNA (chromotoxic effect) liquefaction abnormalities are interpreted to be the result of treatment which affect the depolymerization of DNA, partial dissolution of nucleoproteins or breakage and exchanges of the basic folded fiber unit of chromatids, and/or stripping of protein covering of DNA in chromosomes (Ignacimuthu and Saravana 1994; Asita and Mokhobo 2013). The presence of stickiness in the chromosomes reflected highly toxic effects, usually irreversible which might lead to cell death (Liu et al. 1995).

2. The chromosome kinetic abnormalities (turbogenic effect) are interpreted to be the result of treatment effect of the tested material on spindle mechanism disorder which controls chromosomes mobility and alignment in the cell cytoplasm. It comprised of cells with disturbed chromosomes and cells with lagging chromosomes in addition to clumped chromosomes at metaphases. As illustrated in Table 2, the lower turbogenic effect of Moringa extract may be explained by the severe chromotoxic effect of this extract, which induces increasing percentage of stickiness, and is much higher than its toxic

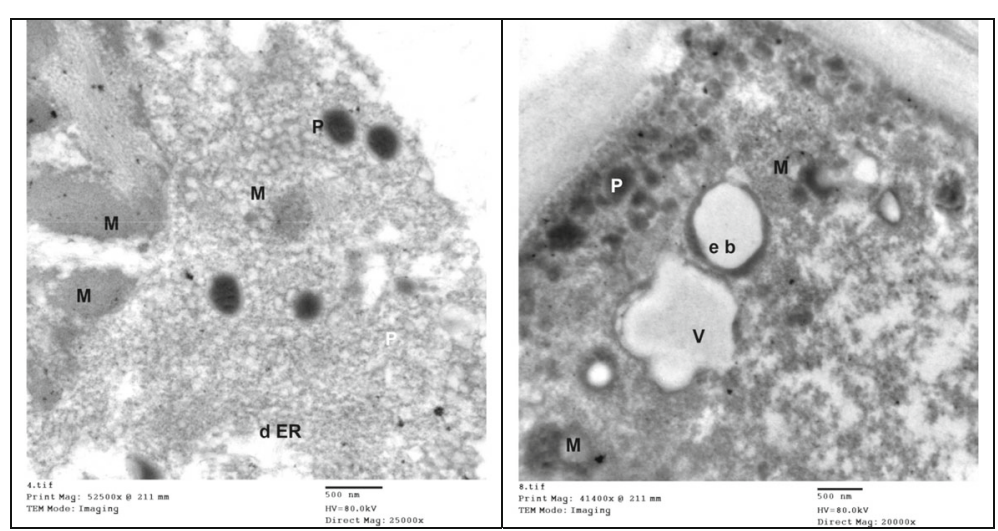

Fig. 5 Ultra-thin section in Allium cepa root tip meristems shows the effect of $3 \mathrm{~h}$ of direct treatment with $20.0 \%$ Moringa extract on cell organelles: mitochondria (M), peroxisomes $(P)$, and dilated endoplasmic reticulum ( $\mathrm{d}$ ER) in addition to vacuole $(V)$ and electron-translucent bodies (eb) 


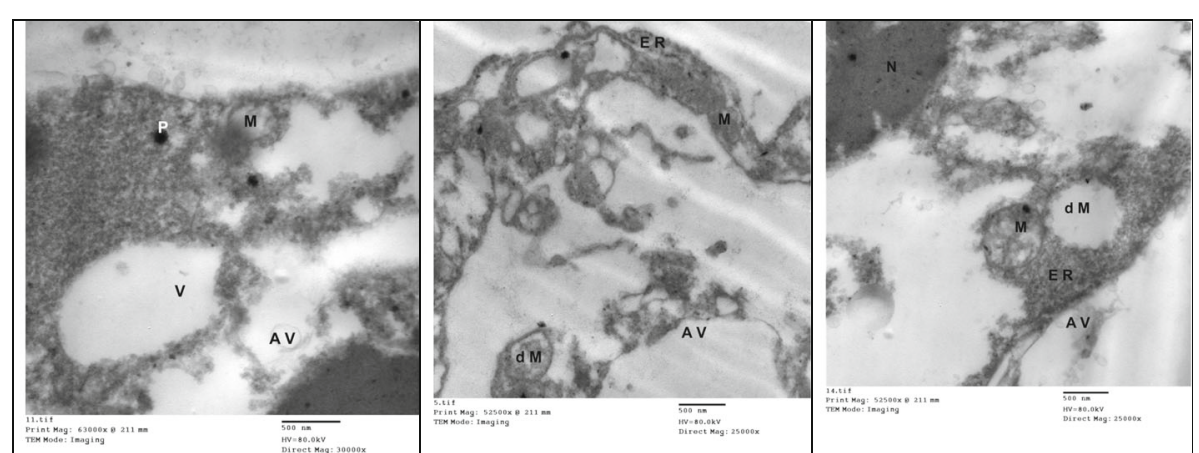

Fig. 6 Ultra-thin section in Allium cepa root tip meristems shows the effect of $3 \mathrm{~h}$ of direct treatment with $5.0 \%$ yeast extract on cell organelles: mitochondria $(M)$, dilated mitochondria $(\mathrm{d} M)$, peroxisomes $(\mathrm{P})$, and dilated endoplasmic reticulum (ER) in addition to vacuole $(V)$ and many autophagic vacuoles (AV) with engulfed organelles

effect on spindle fiber which affects the chromosome mobility in the cell cytoplasm.

3. Chromosome protein core (clastogenic effect) comprised of cells with breakage, fragments, and micro/macronucleus; in our evaluation, the obtained data revealed that the two tested materials were safe without mentioned clastogenic effect if compared with control as micronuclei noticed only after treatment with $10.0 \%$ Moringa extract by percentage $0.6 \%$.

On the cytological level, the appearance of peroxisomes in the cell cytoplasm after treatment with 10.0\% of Moringa extract may reflect the reaction of the cell defensive apparatus toward the treatment stress. Taking in mind that the meristemic cells under treatment with this $10.0 \%$ Moringa extract scored the highest mitotic index which itself is a cell stress but in a positive direction especially to the plant breeders.

It is well known that the mitochondria is a powerhouse of the cell as they convert the ADP into ATP through phosphorylation oxidation reaction to provide cell with energy to carry out its vital functions; it is also considered as a housekeeping organelles in the cytoplasm as it contains enzymes in its inner matrix; if leaks out through pores or ruptures in the outer mitochondria membrane would work on digesting the cell itself in a spontaneous suicide in a phenomenon known as apoptosis (Jones 2002). The presence of such defected mitochondria may give a convincing explanation for the effect of yeast extract on the cell proliferation as the reduction in the mitotic index may result from the reduced level of ATP mainly provided to the cell via mitochondria which extremely affected with yeast extract. Also, it is well known that the endoplasmic reticulum plays an essential role in spindle formation and transport chemically modified materials to different parts of the cell; if become dilated as a result of accumulation of the secreted incompetent materials within it or ruptured or even stressed would drive the cell to self-killing depending on the degree of damage. The presence of such defected endoplasmic reticulum after treatment with the yeast extract may give another explanation for the chromosomes kinetic abnormalities as a result of spindle disorder. Also, it is well known that the

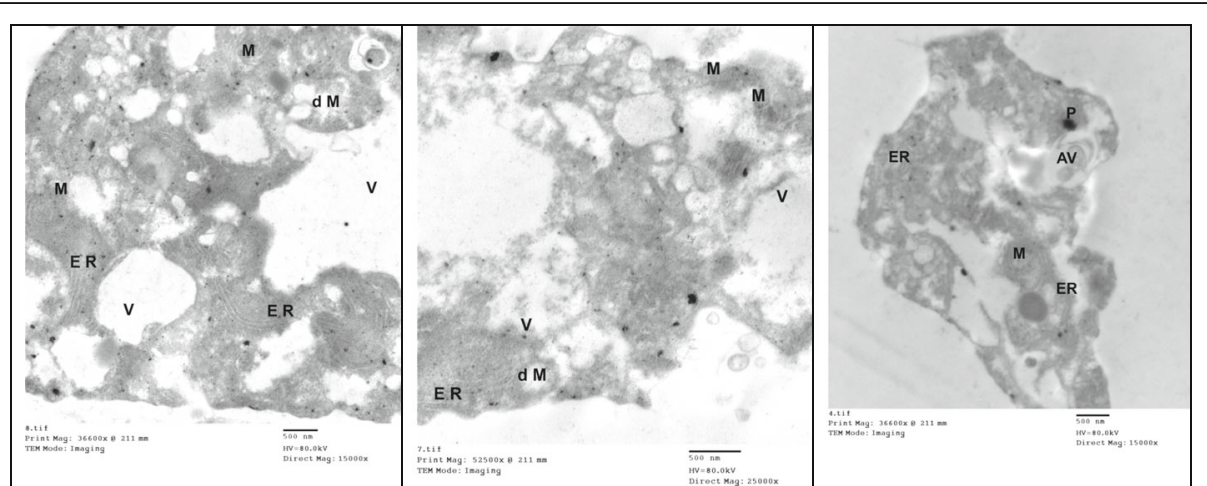

Fig. 7 Ultra-thin section in Allium cepa root tip meristems shows the effect of $3 \mathrm{~h}$ of direct treatment with 10.0\% yeast extract on cell organelles: mitochondria $(M)$, dilated mitochondria $(\mathrm{dM})$, peroxisomes $(P)$, and dilated endoplasmic reticulum (ER) in addition to vacuole $(V)$ and many autophagic vacuoles (AV) with engulfed organelles 


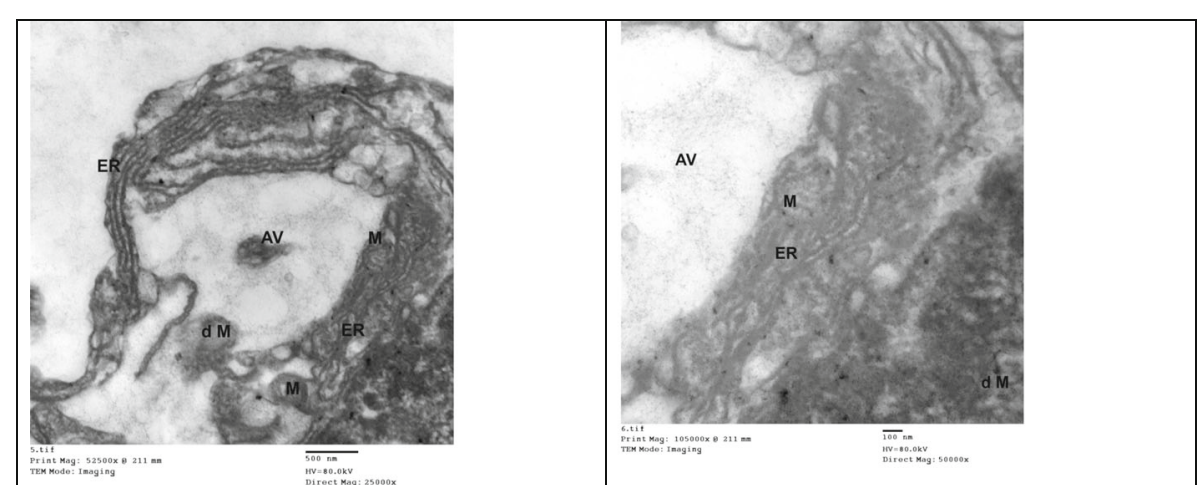

Fig. 8 Ultra-thin section in Allium cepa root tip meristems shows the effect of $3 \mathrm{~h}$ of direct treatment with 20.0\% yeast extract on cell organelles: mitochondria (M), dilated mitochondria (dM), and accumulated endoplasmic reticulum (ER) wrapped around other undistinguishable organelles in addition to huge autophagic vacuole (AV) with engulfed organelles

endoplasmic reticulum and mitochondria are organelles known as a device for protein synthesis which in turn reflects the activation of genes. The formation of dilated endoplasmic reticulum and the presence of numerous undifferentiated mitochondria may explain the gradual decrease in protein synthesis as the deleterious effect on them may block RNA synthesis or translation process as previously reported by Lord et al. (1991). On the other hand, the electron-translucent bodies are considered as a mechanism of recovery of damaged organelle because it reduces the transport of substances through the mitochondria pores (Selga et al. 2005).

The notable effect of the yeast extract on the cytoplasmic vital organelles may be attributed to its effect on the cell cytoplasm PH which is 7.4 in normal conditions where the cytoplasmic organelles can do their accurate function, as it is well known that yeast produces alcohol as a result of its anaerobic respiration which in turn changes the $\mathrm{PH}$ of the treated root tip cells. The alcohol-induced mitochondria and ER stress response fits this theory, because alcohol easily crosses the cellular membranes and affects all compartments inside the cell. Alcohol also impairs autophagy and triggers the lysosome and peroxisomes stress response to increase (Cheng 2015; Lugea et al. 2015).

\section{Conclusion}

After getting these two natural fertilizers investigated on both cytology and cytogenetic levels, the yeast extract shows to somewhat extent the more having remarkable cytological effect; their effect may be attributed to the mode of action of its extract on the $\mathrm{PH}$ of the cell cytoplasm of root tip meristems; by the same time, the higher used concentration of Moringa extract shows higher chromotoxic effect on chromosomal DNA despite it shows high proliferate effect on the treated root tip cells. To achieve the least mutagenic effect, lower concentrations might be used for the two bio-fertilizers under investigation.

\section{Abbreviations}

ADP: Adenine di-phosphate; ATP: Adenine tri-phosphate;

DNA: Deoxyribonucleic acid; ER: Endoplasmic reticulum; MI: Mitotic index

\section{Acknowledgements}

The authors wish to express their deep thanks to the "Plant Moringa Propagation Unit," National Research Center, Giza, Egypt, for kindly afforded the Moringa oleifera leaf extract.

\section{Authors' contributions}

This work was carried out in collaboration between all authors. RTA and FIM designed the study, wrote the protocol, participated in the lab work, and wrote the first draft of the manuscript. EMA-G, ZME managed the lab work of the study and managed the literature searches. EMH managed the paper organization. All authors read and approved the final manuscript.

\section{Funding}

The technical work of this research no. AR111109 was funded financially by the Scientific Research Projects Sector-National Research Centre, Egypt "NRC/ VPRA/GDRPADU/FSEIRPC/F26," to complete and conduct the transmission electron microscopy investigations of this research.

\section{Availability of data and materials \\ Not applicable.}

Ethics approval and consent to participate Not applicable.

\section{Consent for publication}

Not applicable.

\section{Competing interests}

The authors declare that they have no competing interests.

Received: 30 May 2019 Accepted: 29 July 2019

Published online: 22 August 2019

\section{References}

Abbas SM (2013) The influence of biostimulants on the growth and on the biochemical composition of Vicia faba CV. Giza 3 beans. Rom Biotechnol Lett 18:2

Abdalla MM (2013) The potential of Moringa oleifera extract as a biostimulant in enhancing the growth, biochemical and hormonal contents in rocket (Eruca vesicaria subsp. sativa) plants. Inte J Plant Physiol Biochem 5(3):42-49

Abdel-Salam AZE, Soliman KA, Hassan HZ (1997) The mutagenic potentialities of two organophosphorus compounds using different biological systems. Egypt J Genet Cytol. 26:19-21

Ali RT (2009) Cytological and cytogenetic effects of two insecticidal active plant extracts on Vicia faba plants. M.SC. Thesis, collage of girls, Ain Shams Univ., Cairo, Egypt 
Arcara PG, Ronchi VN (2014) Effect of ethyl alcohol on the mitotic cycle of Allium cepa root meristems. Int J Cytol Cytosystematics Cytogenet 20(3):229-232

Asita AO, Mokhobo MM (2013) Clastogenic and cytotoxic effects of four pesticides used to control insect pests of stored products on root meristems of Allium cepa. Environ Nat Resour Res. 3(2):133-145

Cheng J (2015) Review advances and new concepts in alcohol-induced organelle stress, unfolded protein responses and organ damage. Biomolecules 5:10991121

Dinkha RF, Elkhazraji TO (1990) Natural and fungus function science, University of Slah El-Din, Ministry of High Education, Iraq. (in Arabic).

El-Awadi H (1996) The mutagenic effect of some chemical fertilizers on Allium cepa and Vicia faba plant. Ph.D. Thesis. Bot. Dept. Fac. Of science Ain-Shams University Cairo Egypt.

Fuglie $L J$ (2000) The miracle tree: Moringa oleifera: natural nutrition for the tropics. The multiple attributes of Moringa. Publisher Church World Service P172.

Gadano A, Gurni A, Lopez P, Ferraro G, Carballo M (2002) In vitro genotoxic evaluation of the medicinal plant Chenopodium ambrosioides $L$. J Ethnopharmacol 81:11-16

Gagliardi L, Shain DH (2013) Is intracellular pH a clock for mitosis? Theor Biol Med Model. 10:8

Hanafy MS, Saadawy FM, Milad SMN, Ali RM (2012) Effect of some natural extracts on growth and chemical constituents of Schefflera arboricola plants. $J$ Hortic Sci Ornamental Plants 4(1):26-33

Hidalgo A, Gonzalez-Reyes JA, Navas P, Garcia-herdugo G (1989) Abnormal mitosis and growth inhibition in Allium cepa roots induced by propham and chlorprpham. Cytobios. 57(228):7-14

Ignacimuthu SA, Saravana KP (1994) Effect of endosulfan on root tip cells of Allium cepa. Ecotoxical Environ Monit. 4(3):211-215

Jones A (2002) Dose the plant mitochondria integrate cellular stress and regulate programmed cell death? Trends Plant Sci. 5:225-230

Liu DH, Jaing WS, Wang W, Zhai L (1995) Evaluation of metal ion toxicity on root cells by the Allium test. Israel J Plant Sci. 43:125-133

Lord JM, Hartley MR, Roberts LM (1991) Ribosome inactivating proteins of plants. Semin Cell Biol. 2(1):15-22

Lugea A, Waldron RT, Pandol SJ (2015) Pancreatic adaptive responses in alcohol abuse: role of the unfolded protein response. Pancreatology. https://doi. org/10.1016/j.pan.01.011

Majewska A, Wolska E, Sliwinska E, Furmanowa M, Uranska N, Pietrosuk A, Zobel A, Kuras M (2003) Antimitotic effect G2/M accumulation, chromosomal and ultrastructure changes in merastimatic cells of Allium cepa L., root tips treated with extract from Rhadiola rosa roots. Caryology. 56(2):337-351

Phiri C (2010) Influence of Moringa oleifera leaf extracts on germination and early seedling development of major cereals. Agric Biol J N Amer. 1(5):774-777

Reynolds E (1963) The use of lead citrate at high pH as an electron opaque stain in electron -microscopy. J Cell Biol. 17:208-212

Sarhan AT, Sharif FM (1988) Fungus physiology, Dar-AL-kutub Publication, Mosul Univ. Iraq. (In Arabic)

Selga T, Selga M, Pavila V (2005) Death of mitochondria during programmed cell death of leaf mesophyll cells. Cell Biol Int 29:1050-1056

Sharma AK, Sharma A (1980) Chromosome techniques theory and practice. 3rd ed. Butterworth and Co. Publishers Itd. 145-150.

Türkoğlu Ș (2012) Determination of genotoxic effects of chlorfenvinphos and fenbuconazole in Allium ceparoot cells by mitotic activity, chromosome aberration, DNA content, and comet assay. Pesticide Biochemistry and Physiology.103(3):224-30

Wanas AL (2006) Trails for improving growth and productivity of tomato plants grown in winter. Annals Agric Sci Moshtohor. 44(3):214-231

\section{Publisher's Note}

Springer Nature remains neutral with regard to jurisdictional claims in published maps and institutional affiliations.

\section{Submit your manuscript to a SpringerOpen ${ }^{\circ}$ journal and benefit from:}

- Convenient online submission

- Rigorous peer review

- Open access: articles freely available online

- High visibility within the field

- Retaining the copyright to your article

Submit your next manuscript at $\boldsymbol{\nabla}$ springeropen.com 